\title{
Investigation of Solar Hybrid Electric/Thermal System with Radiation Concentrator and Thermoelectric Generator
}

\author{
Edgar Arturo Chávez Urbiola and Yuri Vorobiev \\ CINVESTAV del IPN, Unidad Querétaro, Libramiento Norponiente 2000, 76230 Querétaro, QRO, Mexico \\ Correspondence should be addressed to Edgar Arturo Chávez Urbiola; echavez@qro.cinvestav.mx
}

Received 16 October 2012; Revised 8 January 2013; Accepted 1 February 2013

Academic Editor: Keith Emery

Copyright (C) 2013 E. A. Chávez Urbiola and Y. Vorobiev. This is an open access article distributed under the Creative Commons Attribution License, which permits unrestricted use, distribution, and reproduction in any medium, provided the original work is properly cited.

\begin{abstract}
An experimental study of a solar-concentrating system based on thermoelectric generators (TEGs) was performed. The system included an electrical generating unit with 6 serially connected TEGs using a traditional semiconductor material, $\mathrm{Bi}_{2} \mathrm{Te}_{3}$, which was illuminated by concentrated solar radiation on one side and cooled by running water on the other side. A sun-tracking concentrator with a mosaic set of mirrors was used; its orientation towards the sun was achieved with two pairs of radiation sensors, a differential amplifier, and two servomotors. The hot side of the TEGs at midday has a temperature of around $200^{\circ} \mathrm{C}$, and the cold side is approximately $50^{\circ} \mathrm{C}$. The thermosiphon cooling system was designed to absorb the heat passing through the TEGs and provide optimal working conditions. The system generates $20 \mathrm{~W}$ of electrical energy and $200 \mathrm{~W}$ of thermal energy stored in water with a temperature of around $50^{\circ} \mathrm{C}$. The hybrid system studied can be considered as an alternative to photovoltaic/thermal systems, especially in countries with abundant solar radiation, such as Mexico, China, and India.
\end{abstract}

\section{Introduction}

Solar hybrid electric/thermal systems using photovoltaic (PV) panels combined with a water/air-filled heat extracting unit were designed and studied in many laboratories during the last three decades [1-10] and now are widely used throughout the world (England, Canada, China, Greece, India, and so forth). Some investigations were made [1116] into the possibilities of using thermoelectric generators (TEGs) in solar hybrid systems, with the conclusion that TEGs can be successfully used in these systems instead of PV panels or together with them. An essential increase in thermoelectric conversion efficiency was achieved during the last decade [17-19], which is quite favorable for this kind of TEG's applications. With the traditional thermoelectric material $\mathrm{Bi}_{2} \mathrm{Te}_{3}$, the peak electric efficiency that could be obtained in such a system is $5 \%$ [16].

Chávez-Urbiola et al. [14] investigated different options of the construction of hybrid solar energy conversion systems using TEGs. They showed that these systems can be efficient (and economic in case of industrial production) even with the use of material and devices that are already available on the market, especially in countries with high solar insolation (Mexico, China, India, etc.). Below we describe the construction and detailed experimental investigation of one of the hybrid systems analyzed in the above-mentioned paper [14], namely, the system with a solar radiation concentrator, TEG, and water-filled heat extracting unit. Circulation of water was achieved by thermosiphon effect. The experiments were performed in Queretaro, Mexico, at $20^{\circ}$ of northern latitude, in March 2012.

\section{Description of the Hybrid System}

A schematic of the system is shown in Figure 1 where the solar radiation flux (1) is concentrated by the mosaic mirror (2) onto the electric/thermal generating unit (3) (details of the TEG are shown in Figure 2) consisting of a radiation absorber (hot plate), TEG array, and a cooling plate that is in direct contact with water-circulating copper tubes. The thermosiphon water loop includes a water storage thermal tank (4) with tubes for water entrance and output.

The radiation-concentrating block consisted of 55 plane mirrors each having a size equal to that of the TEG array 


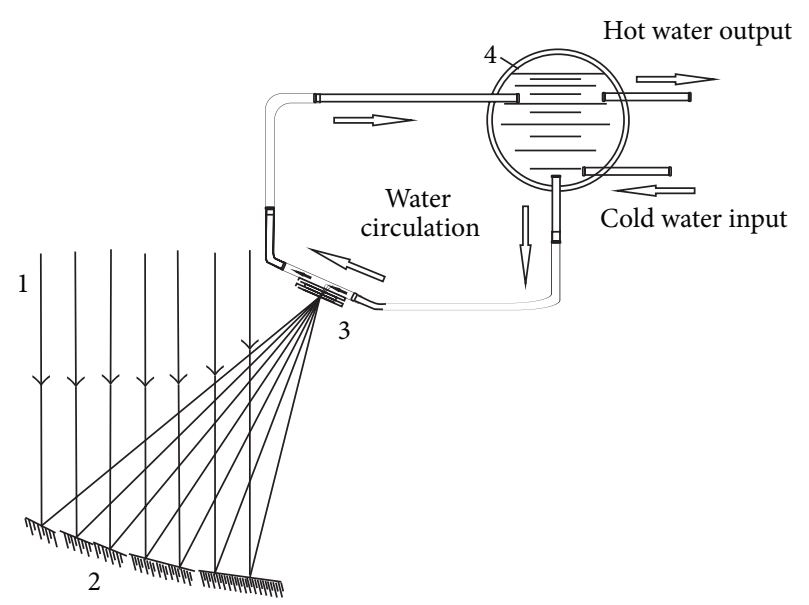

FIgURE 1: A schematic of the hybrid system.

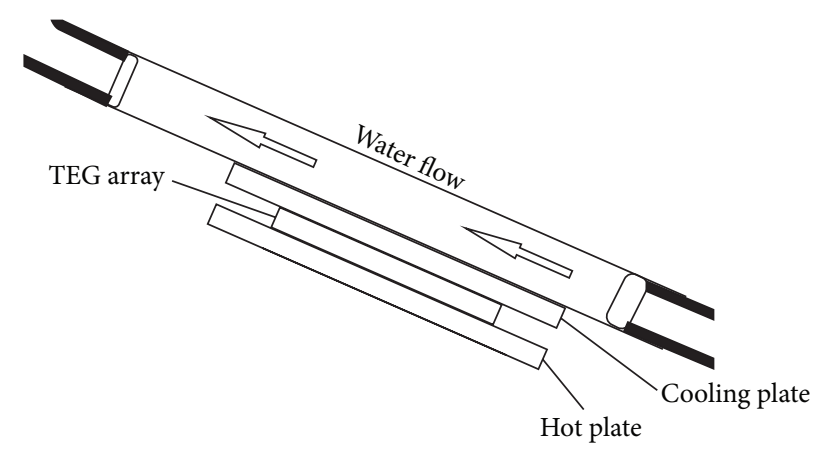

FIgURE 2: Thermoelectric generating (TEG) unit.

$\left(8 \times 12 \mathrm{~cm}^{2}\right)$, providing a concentration ratio (the number of mirrors focused on the heating plate multiplied by the mirror reflecting efficiency) of $\sim 52$, and considering a reflection efficiency of 0.95 . The mirrors were positioned in a parabolic curve, with the focal point over the heating plate of the TEG assembly; the angle of the inclination of each mirror was calculated to achieve this effect. The block (mirror holder) was attached to the 2-axis sun-tracking system (see [20] for details) equipped with 2 pairs of radiation sensors positioned in such a way that the difference in photo response in each couple is zero if the mirror holder is orientated towards the sun, giving the highest illumination of the absorber hot plate. The difference in photo response increases with disorientation (disorientation signal). This difference signal is applied to a PIC16F877 microcontroller, which monitors the system using two geared servomotors.

The TEG array includes 6 generating elements of the type TGM-127-1.4-2.5 based on $\mathrm{Bi}_{2} \mathrm{Te}_{3}$ (made by Kryotherm, Saint Petersburg, Russia; each element is $4 \times 4 \times 0.5 \mathrm{~cm}^{3}$ ). The electrical characteristics of the elements at different temperatures of the operation were given in a previous publication [14].

\section{Calculation of Thermosiphon Loop}

For the thermosiphon solar water heaters, the flow rate of the circulating water is conventionally calculated by equating the pressure head and the friction head. Pressure head is caused by density gradients in the loop, and the friction head is caused by friction in the plumbing arrangement.

The pressure head in the thermosiphon causes flow to occur. This flow in the collector is driven by the weight difference between the hot water column in the return pipe passing through the collector and the cold fluid column in the inlet pipe. The temperature conditions are given by the inlet temperature of the fluid $T_{i}=25^{\circ} \mathrm{C}$ and the inner surface temperature of the hot pipe $T_{s}=40^{\circ} \mathrm{C}$; the density variations in the water along the collector are assumed to be linear for the calculations [21]. The desired maximum temperature in the cooling plate should be around $50^{\circ} \mathrm{C}$.

Imagine an opened thermosiphon loop as a U-tube containing a fluid with one column filled with hot fluid and the other with cold fluid. A height difference, $d h$, results due to the density differences. If instead of U-tube one has a closed loop, this $d h$ leads to a driving force that produces the flow in the loop.

The continuity equations under static equilibrium in case of U-tube can be expressed by

$$
h_{c} \rho_{c}=h_{h} \rho_{h}
$$

and the corresponding pressure head

$$
d h=h_{h}-h_{c},
$$

which is a function of the temperature and the total height of the columns. We can rewrite (2) as a function of the cold- and hot-side densities and considering a total length $L$ :

$$
d h=L\left(2 \frac{\rho_{c}}{\rho_{c}+\rho_{h}}-1\right) .
$$

To determine the thermal driving forces, it is necessary to take into account the values of $T_{i}$ and $T_{s}$. Using the desired values of $T_{i}=25^{\circ} \mathrm{C}$ and $T_{s}=40^{\circ} \mathrm{C}, d h=2.51 \mathrm{~mm}$ is obtained.

The friction head, flow rate, and convective coefficient are interrelated, but they also depend on several physical parameters that must be defined, such as piping type, materials, and pipe length, among others.

Using the Bernoulli equation, an energy conservation analysis can be made. For a pipe system [21] where $p_{1}$ and $p_{2}$ are inlet and outlet pressures, $z_{1}$ and $z_{2}$ are heights, and $v_{1}$ and $v_{2}$ are the corresponding flow velocities, the following can be written in terms of energy:

$$
\frac{p_{1}}{\gamma}+z_{1}+\frac{v_{1}^{2}}{2 g}+h_{A}-h_{R}-h_{L}=\frac{p_{2}}{\gamma}+z_{2}+\frac{v_{2}^{2}}{2 g} v_{2},
$$

where $h_{A}$ is the added energy, $h_{R}$ is the subtracted energy, $h_{L}$ is the energy loss (friction head), $g$ is the acceleration of gravity, and $\gamma$ is the specific weight of the fluid.

On the other hand, it is necessary to include the Darcy equation for friction head $h_{L}$ :

$$
h_{L}=f \frac{L}{D} \frac{v^{2}}{2 g}
$$


where $L$ is the piping length and $D$ is its diameter that depends on the flow rate $v$. As the friction factor $f$ depends on the Reynolds number Re for the laminar flow [21]

$$
f=\frac{64}{\operatorname{Re}}=\frac{64 \mu}{v_{s} D \rho}
$$

for a thermosiphon system, the pressure head is equalized to friction head causing the energy loss

$$
d h=h_{L}
$$

As a consequence, it is necessary to take into account the energy losses due to friction (major losses due to friction and minor losses due to changes in the size and direction of the flow path) in the loop.

The friction head can then be expressed for this case in terms of the friction factor and the flow rate

$$
h_{L}=1.5 \frac{v_{s}^{2}}{2 g}+351.7 \frac{v_{s}^{2}}{2 g} f \text {. }
$$

The first term corresponds to the sum of losses in the inlet and outlet, where it is common to use the estimation friction coefficient $k_{f}=f\left(L_{\mathrm{eq}} / D\right)=1.5$ for systems of this kind [21]. Taking in consideration the laminar flow and equalizing the thermal driving head with the friction head, we get

$$
d h=1.5 \frac{v_{s}^{2}}{2 g}+351.7 \frac{v_{s}}{2 g} \frac{64 \mu}{D \rho} .
$$

Solving (9) for $d h=2.51 \mathrm{~mm}$, a flow rate of $v_{s}=$ $0.0436 \mathrm{~m} / \mathrm{s}$ is obtained.

Once the flow rate is defined, the convective coefficient can be calculated [21]. For the laminar region in the circular pipe and the temperature of $25^{\circ} \mathrm{C}$, the corresponding Nusselt average number is

$$
\overline{\mathrm{Nu}}=3.66+\frac{0.065(D / L) \operatorname{Re} \operatorname{Pr}}{1+[(D / L) \operatorname{Re} \operatorname{Pr}]^{2 / 3}}=5.051, \quad L_{t}<L .
$$

For a thermal length $L_{t} \approx 0.05 \operatorname{Re} \operatorname{Pr} D=5.047 \mathrm{~m}$, the condition $L_{t}<L$ is satisfied, and the convection coefficient can be calculated as

$$
\bar{h}_{c}=\frac{\overline{\mathrm{Nu}} k}{D}=\frac{5.051 \cdot 0.597(\mathrm{~W} / \mathrm{mK})}{0.01892 \mathrm{~m}}=154.84\left(\mathrm{~W} / \mathrm{m}^{2} \mathrm{~K}\right) \text {. }
$$

Once $\bar{h}_{c}$ and $v_{s}$ are determined, we can take them as initial values for the design of the heat exchanger, which starts with computer simulations.

\section{Design of the Heat Exchanger for Electric/Thermal Generating Unit}

In order to determine the optimal configuration of the heat exchanger, several configurations were proposed and evaluated using commercial finite element method (FEM) software
(COMSOL Multiphysics 4.2a). For the flow rate, the value obtained earlier was used: $v_{s}=0.0436(\mathrm{~m} / \mathrm{s})$. The cooling plate temperature must not exceed $50^{\circ} \mathrm{C}$, and the hot plate must be around $200^{\circ} \mathrm{C}$. The solar power transformed into heat in the hot plate is around $200 \mathrm{~W}$ in an area of $0.08 \times 0.12 \mathrm{~m}^{2}$, in correspondence with the $2 \times 3$ array of TEG elements.

The heat exchanger was designed to be as simple as possible, a flat plate attached to the commercial pipes. In Figure 3, the modeling results for several configurations are presented, changing parameters like hot plate location, pipe diameter, piping array, and welding material, among others. In this same figure, simulations from Figure 3(a) to 3(c) are for 1-inch-diameter and from Figure 3(d) to 3(f) are for 3/4inch-diameter type $\mathrm{K}$ copper pipe according to ASTM B-88 standard. The red areas are the hottest and the blue ones the coldest, in accordance with the reference bar in the right side of each model.

After evaluating a wide range of configurations, two options that best meet the conditions were selected and evaluated, and the results are shown in Figure 4. One-inch type $\mathrm{K}$ cooper pipe [21] was used in (a), obtaining a maximum value of $42.4^{\circ} \mathrm{C}$ in the center of the surface (red zone). 3/4-inch type $\mathrm{K}$ pipe was chosen for case (b), leading to a maximum value of $39.4^{\circ} \mathrm{C}$ distributed in a more uniform way along the center of the surface. Thus, option (b) was chosen for the experiment.

\section{Experimental Results}

The actual system studied is shown in the photograph in Figure 5. The positions of the thermocouples are indicated by the red and blue points. The red points also indicate the location of the ink injection, used to give idea of the actual water flow rate. As can be seen in the image, the thermoelectric assembly is illuminated by the concentration block.

The results of the system's electrical and thermal characterization are presented in Figures 6 and 7. To estimate the system's efficiency (both electrical and thermal), the intensity of solar radiation was taken as $950 \mathrm{~W} / \mathrm{m}$, which corresponds to the direct normal irradiance (DNI) in Queretaro, Mexico, at $20^{\circ}$ of northern latitude, at the equinox time of the year. First, the electric power generated by the system during daytime is shown in Figure 6. The measurements were taken with a matched load, so the data shown gives the maximum power available. One can see that the average power was $20 \mathrm{~W}$, thus producing $120 \mathrm{Wh}$ of electric energy between $10 \mathrm{am}$ and $4 \mathrm{pm}$ (the total energy obtained during the day was $175 \mathrm{Wh}$ ). These results correspond to a maximum electric efficiency of the system of $5 \%$, which agrees well with the estimations made in [14] and with the results of modeling [16].

Figure 7 presents the thermal characteristics of the hybrid system. The average hot water tank temperature was approximately $45^{\circ} \mathrm{C}$, which is sufficient for domestic applications. The variations in the thermic efficiency, $\eta_{\text {therm }}=\left(Q_{\text {therm }} / Q_{\text {sol }}\right) \times$ 100 , observed during the time of the experiment give in average of $50 \%$, which is higher than that an traditional $\mathrm{PV} /$ thermal systems. The corresponding thermal power is $200 \mathrm{~W}$, giving the $1.2 \mathrm{kWh}$ of energy in the $6 \mathrm{~h}$ between $10 \mathrm{am}$ 


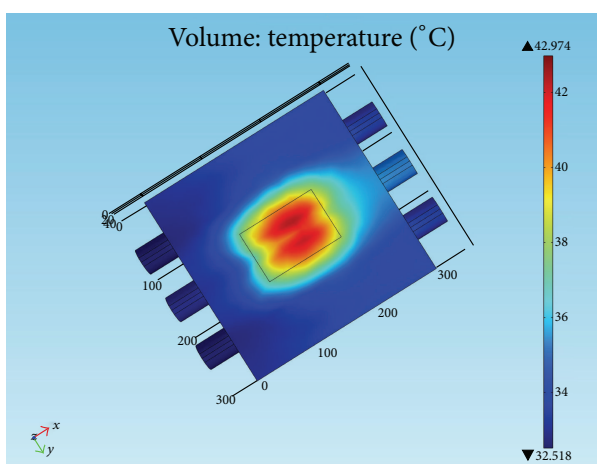

(a)

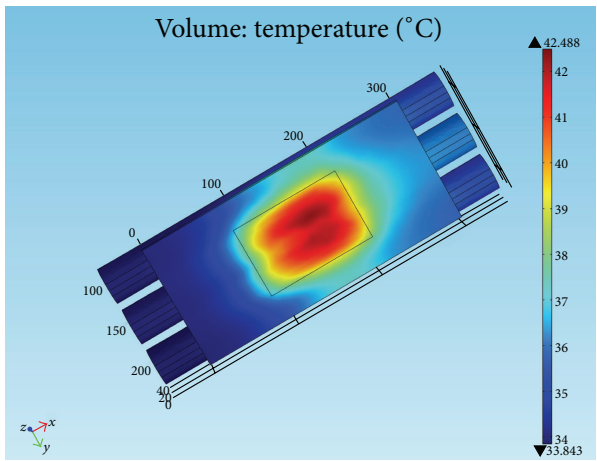

(c)

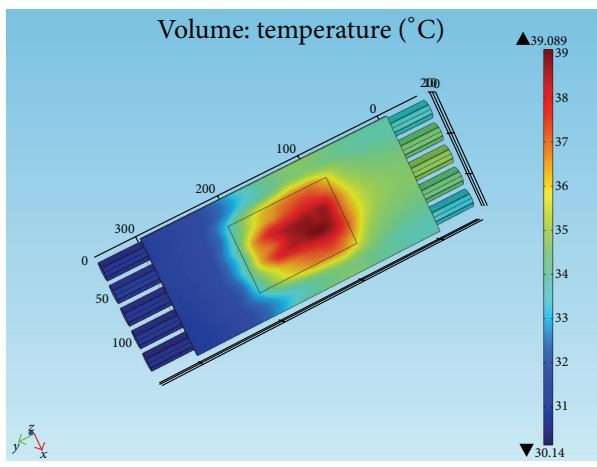

(e)

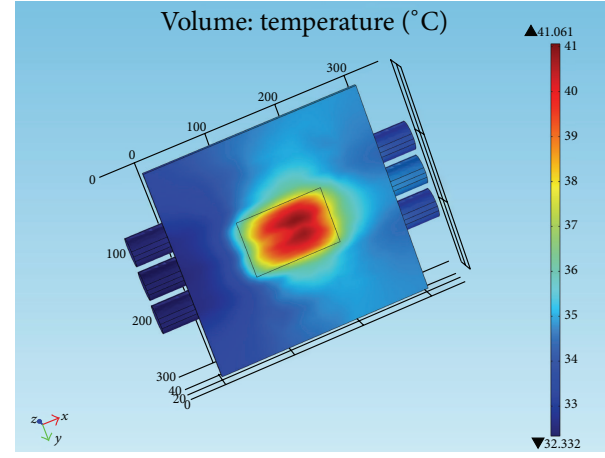

(b)

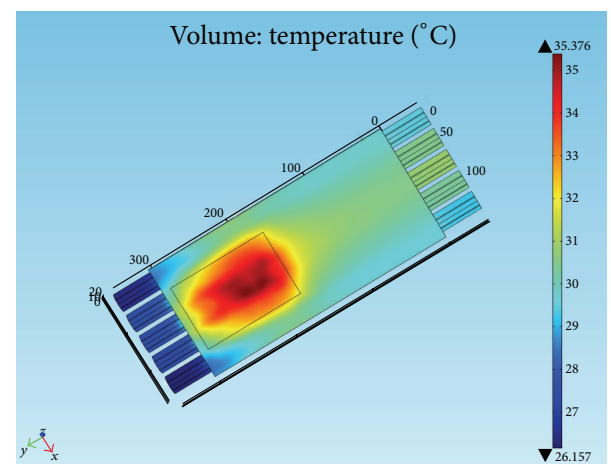

(d)

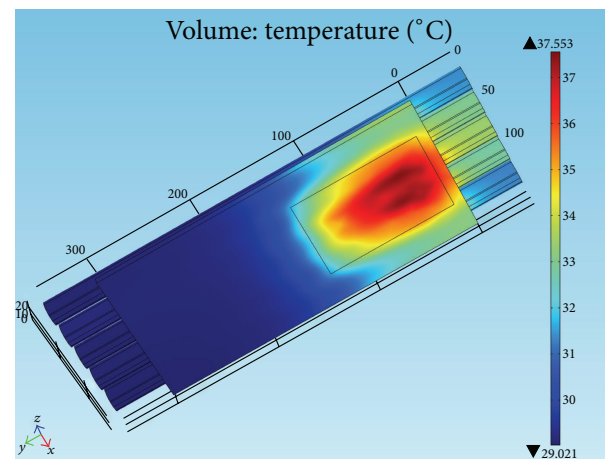

(f)

FIgURE 3: Computer simulations for different configurations (see text); the colors show the temperature distribution.

and $4 \mathrm{pm}$. It can also be seen that the flow rate correlates with the thermal efficiency-higher flow is accompanied by higher efficiency-although the water temperature in the tank is lower.

The cost-efficiency estimation made in our previous publication for the hybrid system studied [14] showed that at industrial production (in quantities of hundreds of systems), the cost of the electric energy generation could be 3-4 US dollars per watt peak, which is almost the same as the cost of the energy generated by PV panels. This is in contrast with the typical case where the cost of energy production in hybrid systems is usually $50 \%$ higher than that in the individual devices. The cost of thermal energy in our system with TEGs is lower than that in the traditional PV/thermal systems because of the larger thermal power.

\section{Conclusions}

Performance of the designed hybrid system in the conditions at Queretaro, Mexico at the equinox time of the year has revealed that a systems electrical efficiency of $5 \%$ and thermal efficiency of $50 \%$ with the estimated cost of the electric 


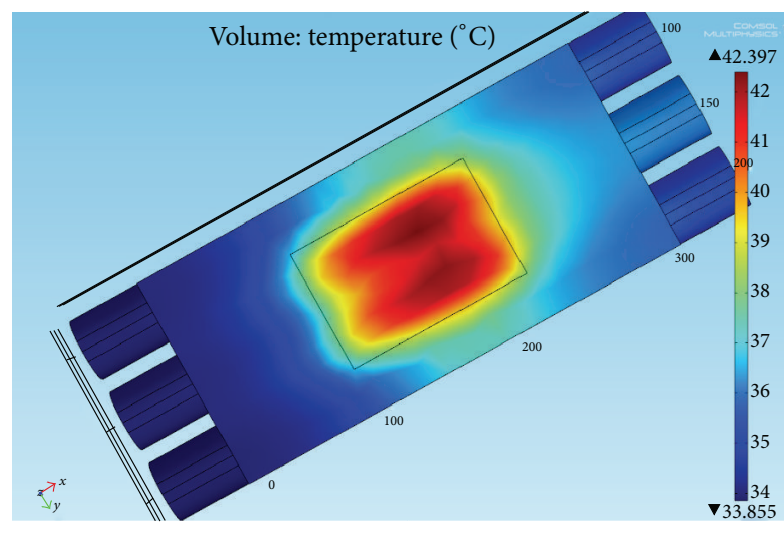

(a)

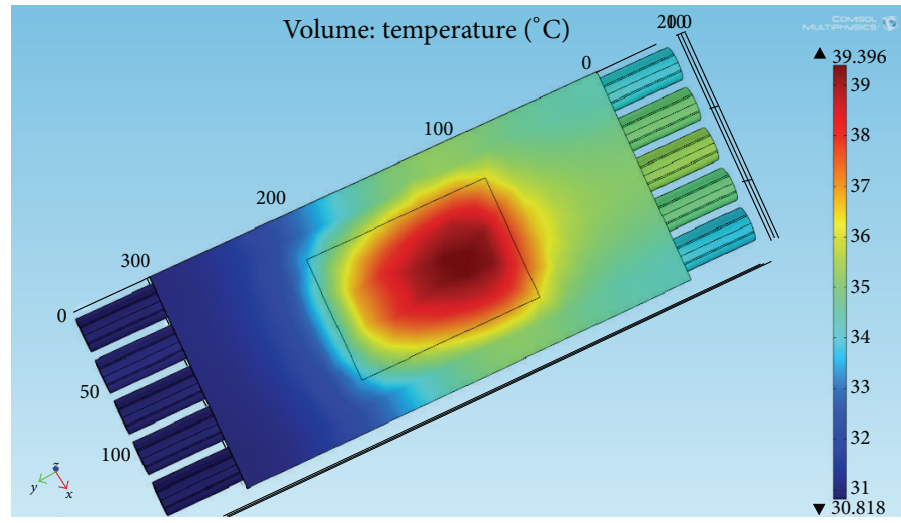

(b)

FIGURE 4: Computer simulations results for (a) $1^{\prime \prime}$ pipes and (b) $3 / 4^{\prime \prime}$ pipes.

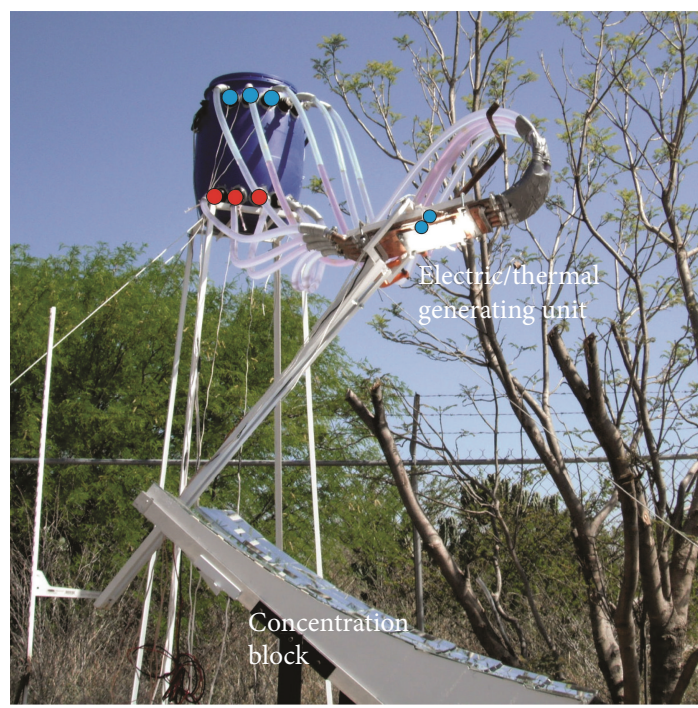

Figure 5: Photograph of the system.

energy production are practically equal to those of the traditional photovoltaic/thermal systems. Thus, we conclude that the solar hybrid system with the concentrator and the thermoelectric generator, even with the existing components, can be considered as a reasonable alternative to the traditional electric/thermal solar hybrid system. Taking into account the rapid progress in the development of new nanostructured and highly efficient thermoelectric materials, we can expect that in the near future performance of the TEG-based systems can surpass that of the traditional solar hybrid systems, in particular, in the solar-rich regions having relatively low latitude.

\section{Nomenclature}

$A_{s}$ : Effective flow area of the piping, $\mathrm{m}$

$C_{p}$ : Specific heat capacity, J/Kg. ${ }^{\circ} \mathrm{C}$

$D$ : Piping diameter, $\mathrm{m}$

$d h$ : Pressure head (thermal driving head), $\mathrm{m}$ $f: \quad$ Friction factor

$g: \quad$ Gravity, $\mathrm{m} / \mathrm{s}$

$h$ : Height, $m$

$h_{A}: \quad$ Energy added to the fluid, J

$h_{c}$ : Cold fluid column height, $\mathrm{m}$

$\bar{h}_{c}: \quad$ Average convection coefficient, $\mathrm{W} / \mathrm{m} \cdot{ }^{\circ} \mathrm{C}$

$h_{h}$ : Hot fluid column height, $\mathrm{m}$

$h_{L}: \quad$ Friction head inside the piping, $m$

$h_{R}$ : $\quad$ Energy removed to the fluid, $\mathrm{J}$

$k_{f}: \quad$ Friction coefficient

$k$ : $\quad$ Thermal conductivity, $\mathrm{W} / \mathrm{mK}$

$L$ : $\quad$ Piping length, $\mathrm{m}$

$L_{\text {eq }}: \quad$ Equivalent pipig length of the minor losses, $\mathrm{m}$

$L_{t}: \quad$ Thermic inlet length, $\mathrm{m}$

$\dot{m}$ : $\quad$ Mas flow, $\mathrm{Kg} / \mathrm{s}$

$\overline{\mathrm{Nu}}$ : Average Nusselt number

$p_{1}: \quad$ Inlet pressure, $\mathrm{N} / \mathrm{m}$

$p_{2}$ : Outlet pressure, $\mathrm{N} / \mathrm{m}$

Pr: $\quad$ Prandtl number

Q: $\quad$ Heat flux, W

$Q_{\text {sun }}$ : Solar heat input W

$Q_{\text {out }}$ : Bottoming heat transfer W

$Q_{\text {therm }}$ : Heat transfer to running water $\mathrm{W}$

Re: $\quad$ Reynolds number

$T_{e}$ : $\quad$ Outlet temperature in the fluid of the heating pipe, ${ }^{\circ} \mathrm{C}$

$T_{i}: \quad$ Inlet temperature in the fluid of the heating pipe, ${ }^{\circ} \mathrm{C}$

$T_{s}$ : $\quad$ Inner surface temperature of the hot pipe, ${ }^{\circ} \mathrm{C}$

$v: \quad$ Flow velocity inside the piping, $\mathrm{m} / \mathrm{s}$

$v_{1}: \quad$ Inlet velocity of the fluid, $\mathrm{m} / \mathrm{s}$

$v_{2}$ : $\quad$ Outlet velocity of the fluid, $\mathrm{m} / \mathrm{s}$

$z_{1}$ : Height at the inlet point, $\mathrm{m}$

$z_{2}$ : Height at the outlet point, $\mathrm{m}$

$\eta_{\text {therm }}:$ Thermic efficiency

$\rho: \quad$ Fluid density, $\mathrm{kg} / \mathrm{m}$

$\rho_{c}: \quad$ Cold fluid density, $\mathrm{kg} / \mathrm{m}$

$\rho_{h}: \quad$ Hot fluid density, $\mathrm{kg} / \mathrm{m}$

$\gamma: \quad$ Specific weight of the fluid, $\mathrm{N} / \mathrm{m}$

$\mu$ : $\quad$ Dynamic viscosity, $\mathrm{Kg} / \mathrm{m} \cdot \mathrm{s}$. 


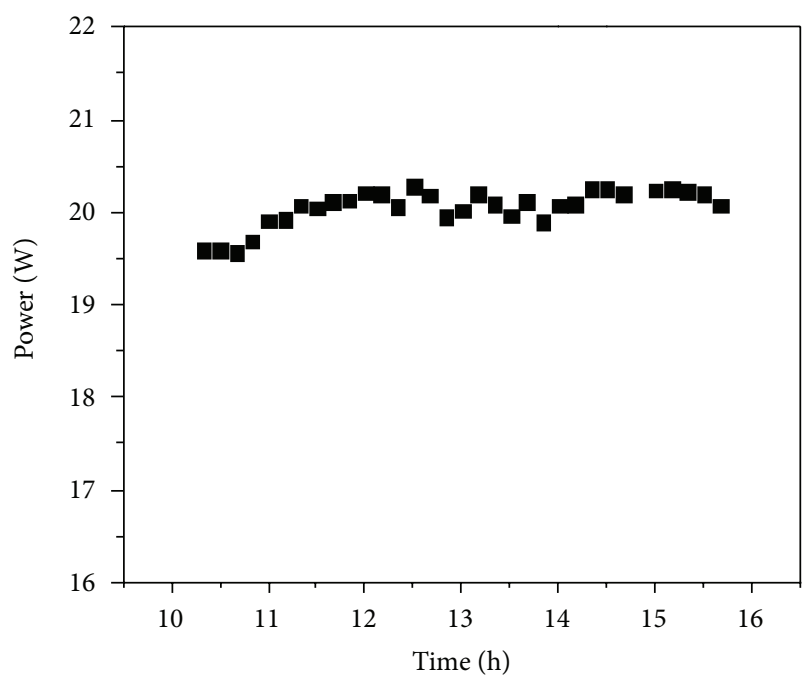

Electric power

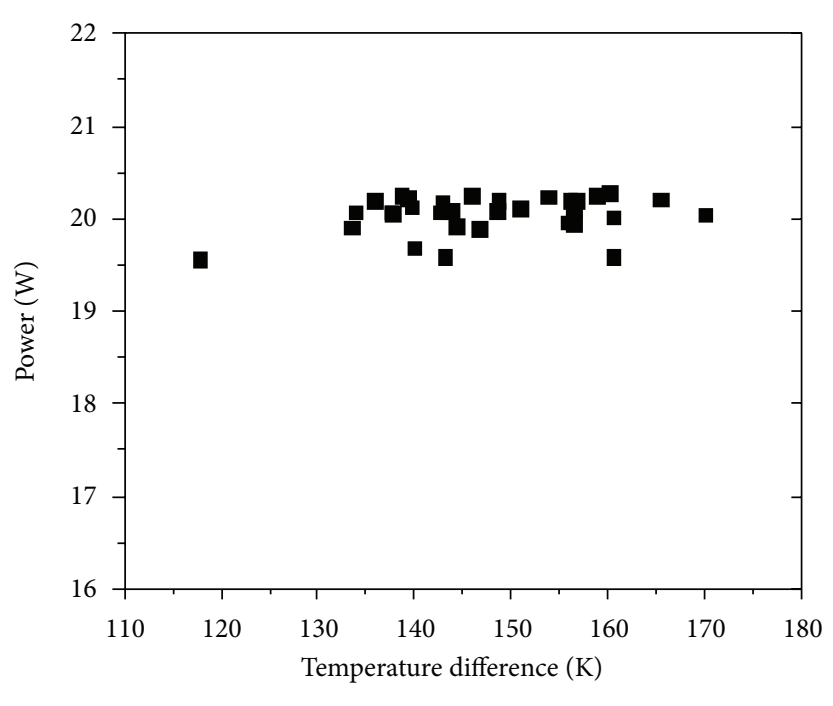

Electric power

(a)

(b)

FIGURE 6: Electric power generation as a function of time of day (a) and as a function of the temperature difference between the TEG plates (b).

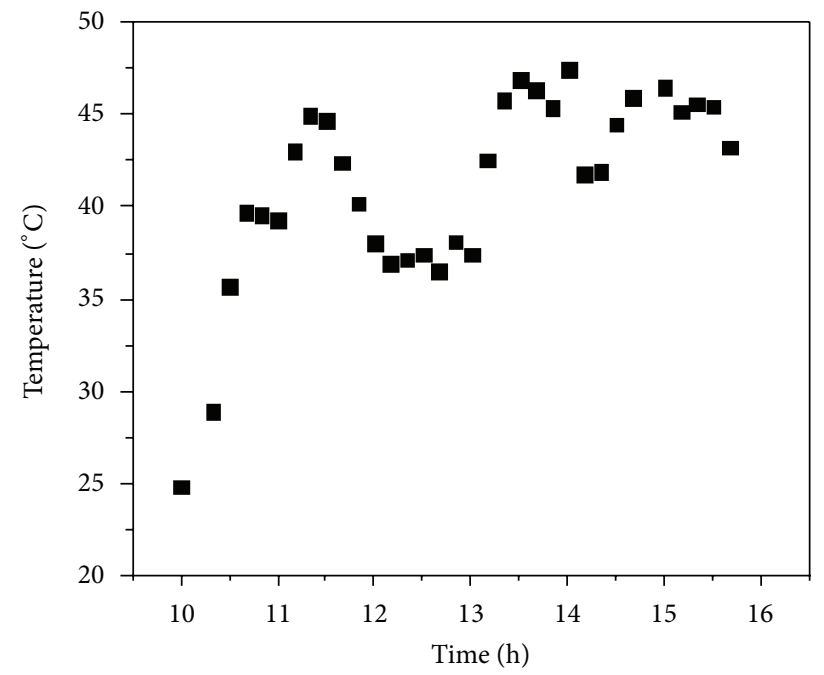

Mean tank temperature

(a)

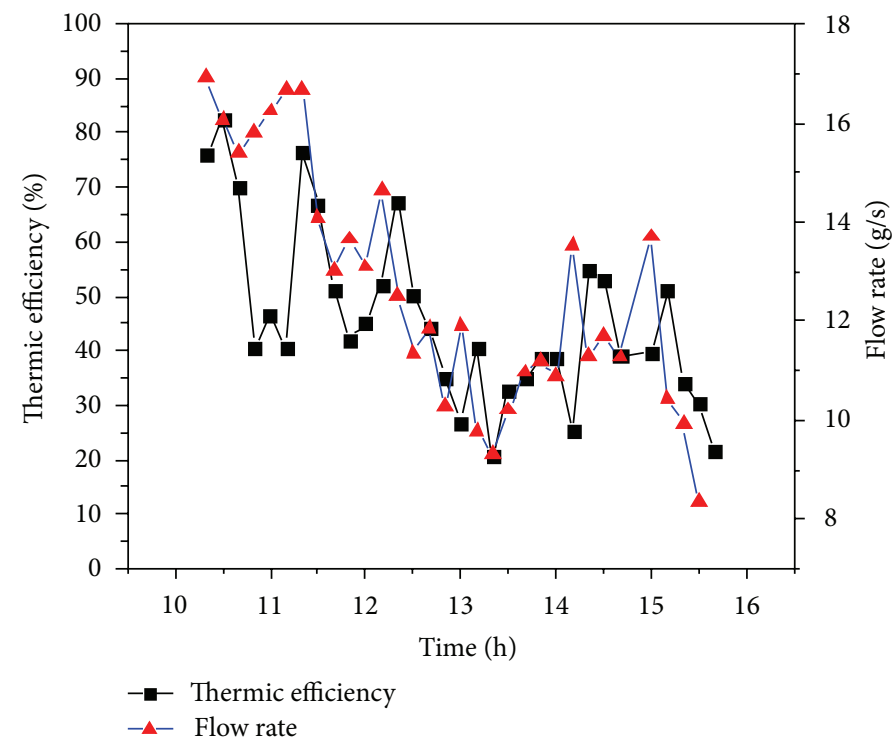

(b)

FIGURE 7: Hot water tank temperature (a) and calculated thermal efficiency of the system and the flow rate in the thermosiphon (b).

\section{Conflict of Interests}

None of the authors of the present work have direct or indirect financial relation with the commercial identity "COMSOL Multiphysics $4.2 \mathrm{a}$ " that might lead to a conflict of interests of any kind for any of the authors.

\section{Acknowledgments}

The authors are grateful to CONACYT for financial support of the project and for the Ph.D. scholarship of E. A. Chávez-Urbiola. They would also like to thank Dr. Mike Boldrick of the US Peace Corps for his review of the paper.

\section{References}

[1] E. C. Kern Jr. and M. C. Russell, "Combined photovoltaic and thermal hybrid collector systems," in Proceedings of the 13th ISES Photovoltaic Specialists, pp. 1153-1115, Washington, DC, USA, June 1978.

[2] P. Raghuraman, "Analytical predictions of liquid and air photovoltaic/thermal, flat-plate collector performance," Journal of Solar Energy Engineering, vol. 103, no. 4, pp. 291-298, 1981.

[3] H. P. Thomas, S. J. Hayter, R. L. Martin, and L. K. Pierce, "PV and PV/Hybrid products for buildings," in Proceedings of the 16th European Photovoltaic Solar Energy Conference and Exhibition, vol. 2, pp. 1894-1897, Glasgow, UK, May 2000. 
[4] H. A. Zondag, D. W. De Vries, W. G. J. Van Helden, R. J. C. Van Zolingen, and A. A. Van Steenhoven, "The thermal and electrical yield of a PV-thermal collector," Solar Energy, vol. 72, no. 2, pp. 113-128, 2002.

[5] J. Aschaber, C. Hebling, and J. Luther, "Realistic modelling of TPV systems," Semiconductor Science and Technology, vol. 18, no. 5, pp. S158-S164, 2003.

[6] Y. Tripanagnostopoulos, "Aspects and improvements of hybrid photovoltaic/thermal solar energy systems," Solar Energy, vol. 81, no. 9, pp. 1117-1131, 2007.

[7] H. A. Zondag, "Flat-plate PV-Thermal collectors and systems: a review," Renewable and Sustainable Energy Reviews, vol. 12, no. 4, pp. 891-959, 2008.

[8] S. Dubey and G. N. Tiwari, "Thermal modeling of a combined system of photovoltaic thermal (PV/T) solar water heater," Solar Energy, vol. 82, no. 7, pp. 602-612, 2008.

[9] A. Ibrahim, M. Y. Othman, M. H. Ruslan, S. Mat, and K. Sopian, "Recent advances in flat plate photovoltaic/thermal (PV/T) solar collectors," Renewable and Sustainable Energy Reviews, vol. 15, no. 1, pp. 352-365, 2011.

[10] Y. Vorobiev, J. González-Hernández, P. Vorobiev, and L. Bulat, "Thermal-photovoltaic solar hybrid system for efficient solar energy conversion," Solar Energy, vol. 80, no. 2, pp. 170-176, 2006.

[11] S. A. Omer and D. G. Infield, "Design optimization of thermoelectric devices for solar power generation," Solar Energy Materials and Solar Cells, vol. 53, no. 1-2, pp. 67-82, 1998.

[12] P. Li, L. Cai, P. Zhai, X. Tang, Q. Zhang, and M. Niino, "Design of a concentration solar thermoelectric generator," Journal of Electronic Materials, vol. 39, no. 9, pp. 1522-1530, 2010.

[13] D. Kraemer, L. Hu, A. Muto, X. Chen, G. Chen, and M. Chiesa, "Photovoltaic-thermoelectric hybrid systems: a general optimization methodology," Applied Physics Letters, vol. 92, no. 24, Article ID 243503, 2008.

[14] E. A. Chávez-Urbiola, Y. Vorobiev, and L. P. Bulat, "Solar hybrid systems with thermoelectric generators," Solar Energy, vol. 86, no. 1, pp. 369-378, 2012.

[15] W. G. J. H. M. V. Sark, "Feasibility of photovoltaic-thermoelectric hybrid modules," Applied Energy, vol. 88, no. 8, pp. 27852790, 2011.

[16] D. Kraemer, K. McEnaney, M. Chiesa, and G. Chen, "Modeling and optimization of solar thermoelectric generators for terrestrial applications," Solar Energy, vol. 86, no. 5, pp. 1338-1350, 2012.

[17] R. Venkatasubramanian, E. Siivola, T. Colpitts, and B. O’Quinn, "Thin-film thermoelectric devices with high room-temperature figures of merit," Nature, vol. 413, no. 6856, pp. 597-602, 2001.

[18] A. Tavkhelidze, G. Skhiladze, A. Bibilashvili et al., "Thermionic converter with quantum tunneling," in Proceedings of the IEEE 22th International Conference on Thermoelectrics, pp. 435-438, August 2002.

[19] L. P. Bulat, V. T. Bublik, I. A. Drabkin et al., "Bulk nanostructured polycrystalline $\mathrm{p}$-Bi-Sb-Te thermoelectrics obtained by mechanical activation method with hot pressing," Journal of Electronic Materials, vol. 39, no. 9, pp. 1650-1653, 2010.

[20] P. Vorobiev and Y. Vorobiev, "Automatic Sun tracking solar electric systems for applications on transport," in Proceedings of 7th International Conference on Electrical Engineering, Computing Science and Automatic Control (CCE '10), pp. 66-70, Chiapas, Mexico, September 2010.

[21] R. L. Mott, Applied Fluid Mechanics, Macmillan, New York, NY, USA, 4th edition, 1994. 

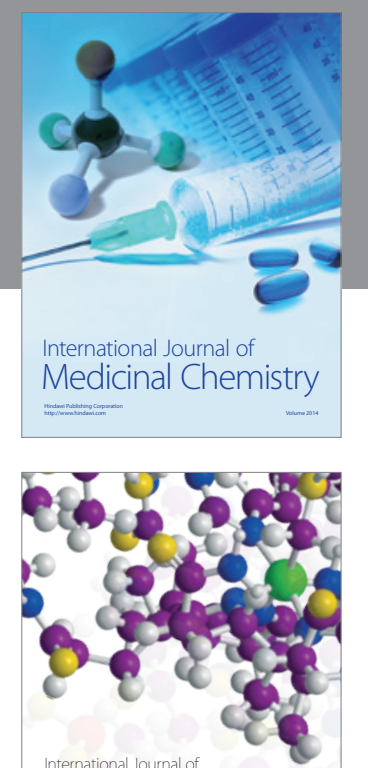

\section{Carbohydrate} Chemistry

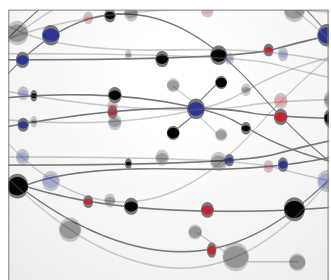

The Scientific World Journal
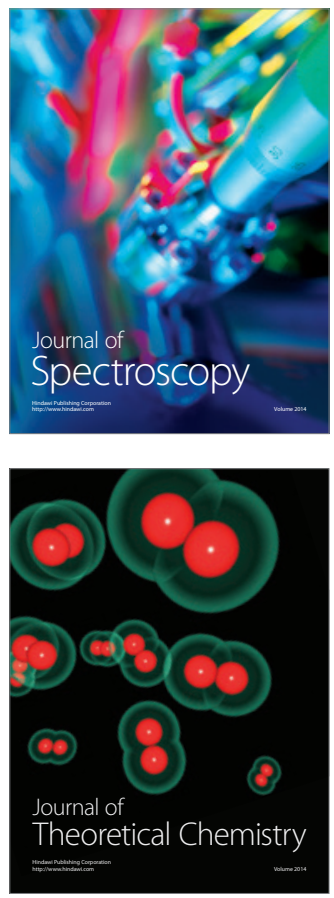
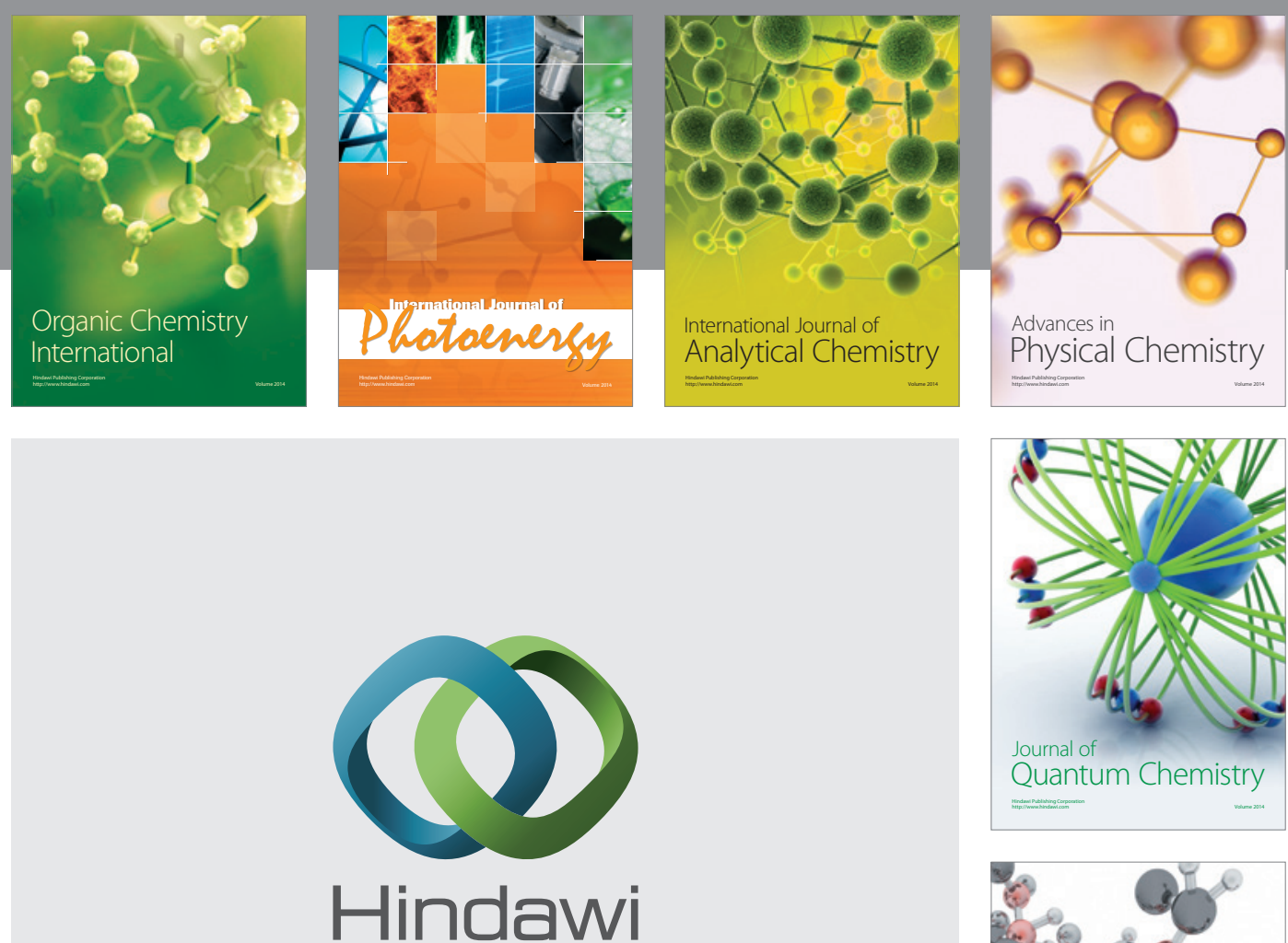

Submit your manuscripts at

http://www.hindawi.com

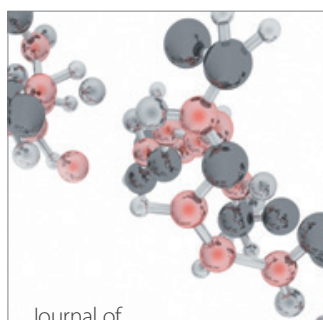

Analytical Methods

in Chemistry

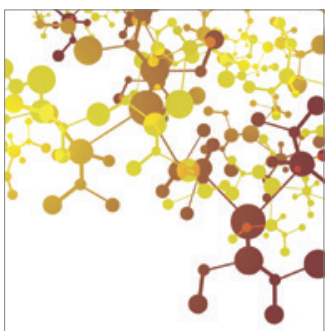

Journal of

Applied Chemistry

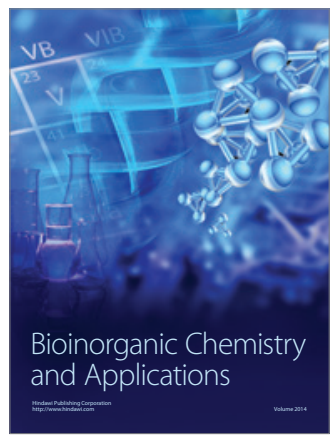

Inorganic Chemistry
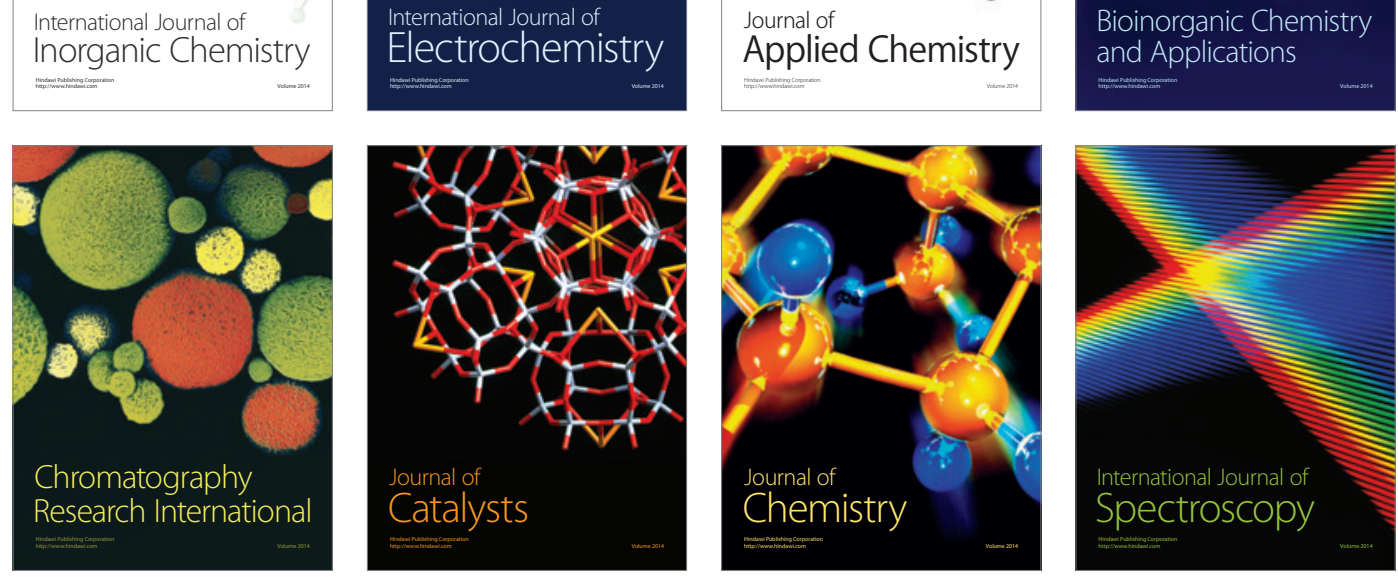